DOI 10.37882/2223-2982.2020.06.25

\title{
АЛГОРИТМИЗИРОВАННАЯ ТЕХНОЛОГИЯ ДИАГНОСТИКИ СТРУКТУРЫ И ДИНАМИКИ ОБУЧЕННОСТИ УЧАЩИХСЯ В СИСТЕМЕ «ШКОЛА-ВУЗ»
}

\section{ALGORITHMIZED TECHNOLOGY FOR DIAGNOSTICS OF STRUCTURE AND DYNAMICS OF TRAINING OF STUDENTS IN THE SCHOOL-UNIVERSITY SYSTEM}

I. Russkih

T. Rodygina

G. Belova

Summary: The article discusses the technology for diagnosing the structure and dynamics of training, an algorithm for using this technology is proposed. The paper presents experimental data on testing the proposed technology in the school-university system.

Keywords: model, technology, diagnostics, training.

\section{Б^ок-схема алгоритма технологии миагностики}

Для диагностики структуры уровней обученности каждого учащегося необходимо регулярно проводить тематическое тестирование, при котором выявляются не только учебные достижения, но и конкретные пробелы в знаниях и умениях учащихся [1]. По данным тестирования проводится индивидуальная диагностика и корректировка степени обученности каждого учащегося. На рис.1 показана предлагаемая нами блок-схема алгоритма технологии диагностики структуры и динамики обученности учащихся и организации управляющего воздействия на процесс обучения [10].

Ориентация построения учебного процесса на определенный при диагностике начальный уровень обученности студентов позволяет оптимизировать процесс обучения и способствует повышению качества подготовки специалистов [3]. Для определения начального уровня обученности учащихся на первом занятии по физике проводится входное тестирование. Это необходимо, чтобы определить, с каким контингентом учащихся мы начинаем учебный процесс, для планирования последующих этапов технологии учебного процесса, выбора его оптимального варианта [6].

Так как основной контингент поступающих в Ижевскую государственную сельскохозяйственную академию составляют выпускники школ выходного дня и школ

\author{
Русских Ирина Тачровна \\ К.п.н., дочент, Ижевская государственная \\ сельскохозяйственная академия \\ Rit19861990@mail.ru \\ Родыгина Тамара Александровна \\ К.п.н., доцент, Ижевская государственная \\ сельскохозяйственная академия \\ 9058748130@mail.ru \\ Белова Галина Михайловна \\ К.n.н., дочент, Ижевская государственная \\ сельскохозяйственная академия \\ fnpo@izhgsha.ru
}

Аннотация: В статье рассматривается технология диагностики структуры и динамики обученности, предложен алгоритм использования данной технологии. В работе приводятся экспериментальные данные по апробации предлагаемой технологии в системе «школа-вуз».

Ключевые слова: модель, технология, диагностика, обученность.

аграрного направления, организованных при академии, то в качестве входного тестирования можно воспользоваться результатами итогового тестирования, проводимого в этих школах[5].

\section{Структурирование учебного материала}

Для проведения тематического тестирования весь учебный материал семестра разбит на семь тематических модулей. Модульно-тематический подход к построению учебного процесса обеспечивает неоднократную проработку обучающимися студентами всего учебного материала. Изучение модулей идет последовательно, внутри каждого тематического модуля материал располагается и изучается с постепенным нарастанием объема учебного материала и уровнем умений тем в соответствии с принятой таксономической моделью[6].

После изучения каждого тематического модуля проводится текущий тематический тестовый контроль. Итоговые тестовые баллы, учитывающие надежность теста и погрешность тестирования, суммируются по всем тематическим модулям и служат индивидуальной характеристикой уровня обученности студента.

Для модульно-тематического тестирования используются 35 тестовых карт, содержащих более пятисот заданий на деятельность разного уровня умений. Все задания теста закрытого типа с выборочным ответом. 


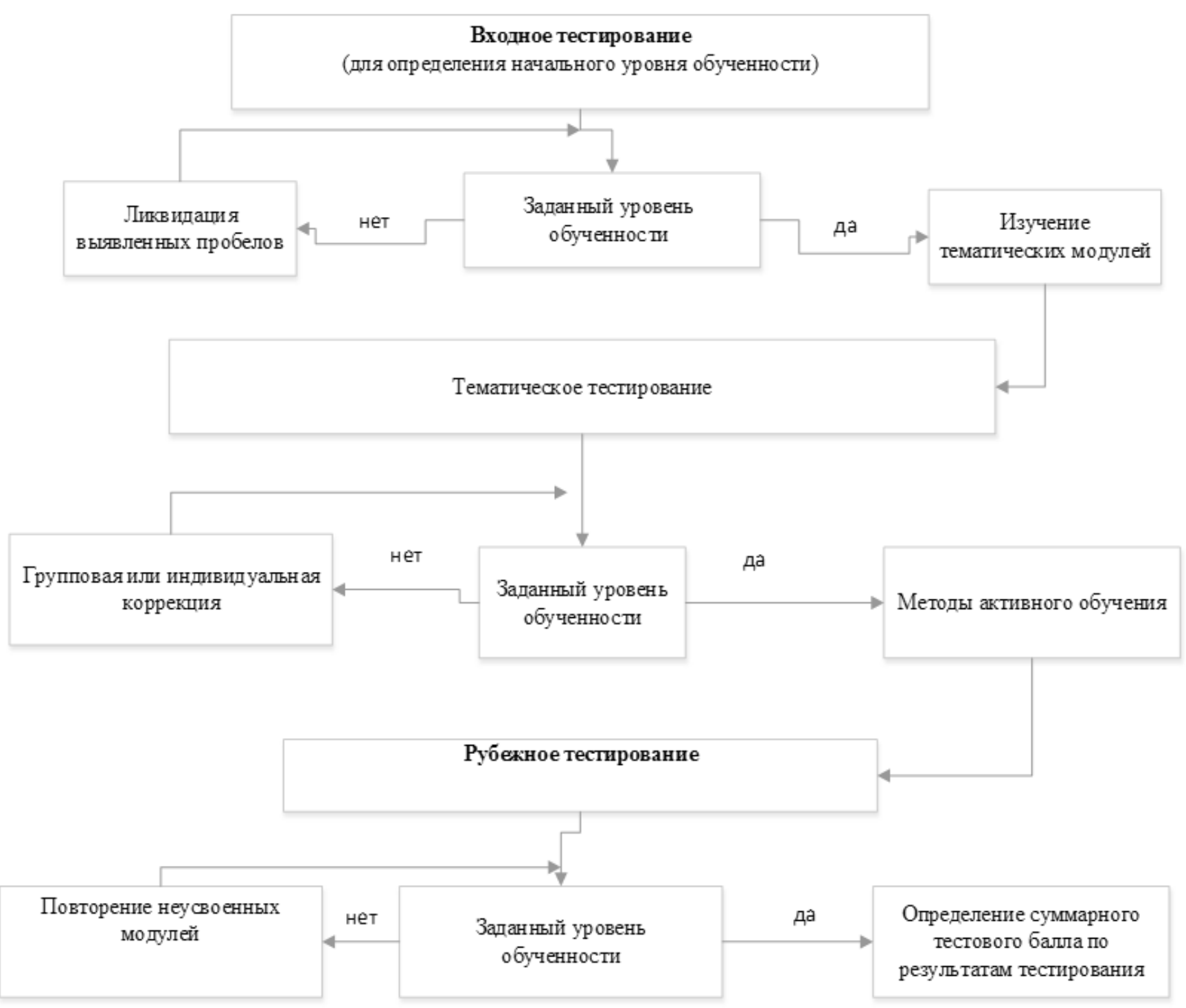

Рис.1. Блок-схема алгоритма применения технологии диагностики изучения структуры и динамики обученности учащихся.

Каждый тематический модуль представлен параллельными вариантами тестов, содержащих от 15 до 18 тестовых заданий, что позволяет исключить заимствование ответов. В дальнейшем, студентов имеющих одинаковый вариант, можно объединить в малые группы. Для проведения дифференциальной диагностики и непрерывного мониторинга структуры уровней обученности индивидуальные тестовые баллы обучаемых суммируются по градациям знаний и уровням умений раздельно [10].

\section{Оченка уровня обученности}

Для оценки степени усвоения учебного материала используется коэффициент обученности, который определяется отношением правильно выполненных заданий к общему числу заданий в тесте, выраженным в процентах:

$$
\mathrm{K}_{\alpha}=\frac{\mathrm{a}}{\mathrm{p}} \cdot 100 \%
$$

где а - число правильно выполненных заданий в тесте, p - общее число заданий в тесте.

Коэффициенты обученности рассчитываются отдельно для трех уровней умений. По результатам тематического тестирования для каждого обучаемого строятся карты обученности [10]. Карты обученности позволяют определить не только уровень обученности учащегося, но и качество структуры знаний в обучении. При оценке уровня обученности тестируемого по итоговому коэффициенту обученности не учитывается трудность правильно выполненных им заданий, не учитывается легкость нерешенных тестируемых заданий. Информацию индивидуальных карт обученности можно использовать для анализа динамики усвоения новых знаний учащимся 
и управления процессом обучения данного учащегося. В результате анализа индивидуальных карт обученности преподаватель дает учащимся рекомендации повторить тему, либо обратить внимание на знание физического материала, на необходимость обработки умений выполнения типовых заданий или развитие способностей к эвристическому анализу нетиповых задач, используя подготовленные для этой цели методические пособия.

Измерение обученности с использованием тестовых форм позволяет оценить эффективность различных методик, используемых преподавателями в процессе обучения, фактический уровень подготовки обучаемых по данной дисциплине, соответствие этого уровня требованиям ГОС по дисциплине.

\section{Ошенка Аинамики обученности}

Методика определения качества знаний лишь по коэффициенту обученности позволяет сравнивать уровни обученности каждого студента друг с другом, но не дает обобщенной информации о динамике $\mathrm{K}_{\alpha}$ по данной группе в целом. Для оценки динамики обученности предлагается использовать следующие статистические показатели[2,12]: среднее значение $\left(\mathrm{x}_{\mathrm{cp}}\right)$ и показатели вариации (дисперсию, асимметрию и эксцесс).

Для оценки величины рассеивания тестовых баллов относительно среднего значения служит дисперсия (Д) и среднее квадратическое отклонение (б), определяемые по формулам (2) и (3)

$$
\begin{aligned}
& Д=\left(M_{2}-\left(M_{1}\right)^{2}\right) h^{2} \\
& \sigma=\sqrt{Д}
\end{aligned}
$$

Центральные моменты определялись по формулам (4-6)

$$
\begin{aligned}
\mathrm{M}_{1} & =\frac{\sum N_{i} U_{i}}{N} \\
U_{i} & =\frac{x_{i}-x_{\mathrm{cp}}}{h} \\
\mathrm{M}_{2} & =\frac{\sum N_{i} U_{i}^{2}}{N}
\end{aligned}
$$

Где $\mathrm{N}_{\mathrm{i}}$ - число индивидуальных баллов, падающих интервал,

$\mathrm{N}$ - общее число учащихся, принимающих участие в тестировании,

$\mathrm{h}$ - шаг выборки.

Дисперсия и стандартное отклонение характеризуют величину рассеивания тестовых баллов относительно среднего значения, однако они не могут показать характер существующих в группе отклонений. Для этого служит показатель асимметрии распределения, определяемый через центральные моменты третьего порядка.

Асимметрия характеризует скошенность кривой распределения в одну или другую сторону от центра группирования, т.е. среднего значения. Для нормального распределения асимметрия равна нулю (см. рис.2). Если большая часть кривой распределения находится справа от среднего значения, то асимметрия является отрицательной. Отрицательная асимметрия более желательна в методике каждого усвоения для процесса обучения, т.к. большая часть обучаемых имеет степень усвоения выше среднего значения. В этом случае мода лежит правее среднего значения. Асимметрия определяется по следующей формуле[12]:

$$
\begin{gathered}
\mathrm{A}_{\mathrm{s}}=\frac{m_{3}}{\sigma^{3}} \\
\mathrm{~m}_{3}=\left(\mathrm{M}_{1}-3 \mathrm{M}_{1} \mathrm{M}_{2}+2\left(\mathrm{M}_{1}\right)^{3}\right) \mathrm{h}^{3} \\
\mathrm{~m}_{4}=\left(\mathrm{M}_{4}-4 \mathrm{M}_{1} \mathrm{M}_{3}+6\left(\mathrm{M}_{1}\right)^{2} \mathrm{M}_{2}-3\left(\mathrm{M}_{1}\right)^{4}\right) \mathrm{h}^{4}
\end{gathered}
$$

где m3 и m4- центральные эмпирические моменты третьего и четвертого порядка;

Для оценки «крутости» распределения, т.е. большего или меньшего подъема кривой распределения по сравнению с нормальным распределением используется эксцесс (см. рис.2). При увеличении разброса коэффициента обученности эксцесс получается отрицательным, при этом распределение более низкое и пологое, при положительном эксцессе распределение более высокое и крутое чем нормальное, что характеризует, что коэффициент обученности большинства обучаемых близок к среднему значению по группе. В процессе обучения педагог должен стремиться к положительному эксцессу. Эксцесс определяем по следующей формуле:

$$
\mathrm{e}_{\mathrm{k}}=\frac{m_{4}}{\sigma^{4}}-3
$$

Отсутствие симметрии в гистограмме оказывает определенное влияние на соотношение между модой и средним значением. Если большинство оценок расположено слева от вершины полигона частот, то среднее примет минимальное значение, мода - максимальное, а медиана будет располагаться между ними (см. рис.2). Для нормального распределения эксцесс и асимметрия равны нулю.

\section{Модель полного усвоения}

Признаком полного усвоения учебного материала является отрицательная симметрия и положительный эксцесс [10].

Отличительной чертой обучения на основе модели полного усвоения является фиксация учебных результатов на достаточно высоком уровне, которого должны 

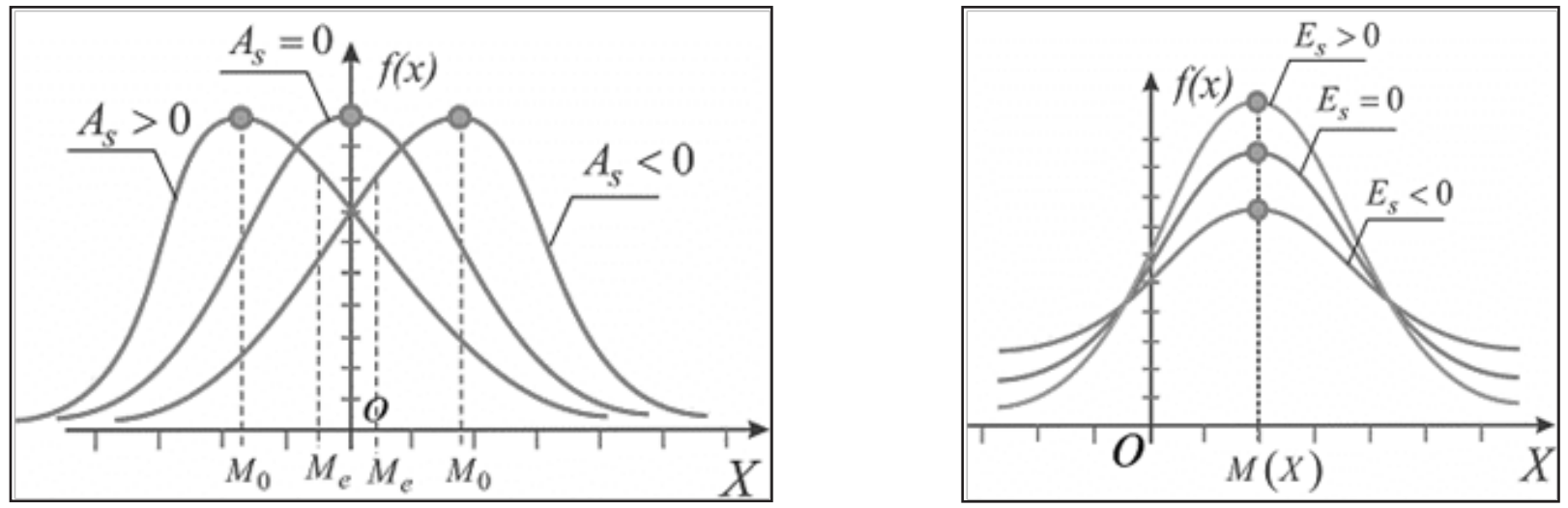

Рис. 2. Кривые распределения обученности для различных значений эксцесса и ассиметрии

Таблица 1

Карта обученности № . Номер темы

\begin{tabular}{|c|c|c|c|c|c|}
\hline \multirow{5}{*}{$\begin{array}{l}\text { Уровень } \\
\text { умений }\end{array}$} & Итоговый & МИ..... & БИ & ПИ & БПИ \\
\hline & Эвристический (3) & (M3) & (Б3) & (ПЗ) & БПЗ \\
\hline & Операционный (2) & (M2) & (Б2) & (П2) & БП2 \\
\hline & Фактологический (1) & (M1) & (Б1) & (П1) & БП1 \\
\hline & 0бъём знаний & Минимальный (М) & Базовый (Б) & Программный (П) & Итоговый (И) \\
\hline
\end{tabular}

Таблица 2

Структура тематических тестов

\begin{tabular}{|l|c|c|c|c|}
\hline Уровень/объём & Минимальный & Базовый & Программный & Полный \\
\hline Фактологический & $10 \%$ & $10 \%$ & $15,5 \%$ & $35,5 \%$ \\
\hline Операционный & $5 \%$ & $15 \%$ & $15,5 \%$ & $35,5 \%$ \\
\hline Эвристический & $5 \%$ & $10 \%$ & $14 \%$ & $29 \%$ \\
\hline Все уровни & $20 \%$ & $35 \%$ & $45 \%$ & $100 \%$ \\
\hline
\end{tabular}

Таблица 3

Статистические параметры обученности

\begin{tabular}{|c|c|c|c|c|c|c|c|c|c|c|}
\hline \multirow[t]{2}{*}{ Уровень } & \multicolumn{2}{|c|}{ Среднее } & \multicolumn{2}{|c|}{ размах } & \multicolumn{2}{|c|}{ СКO } & \multicolumn{2}{|c|}{ асимметрия } & \multicolumn{2}{|c|}{ эксцесс } \\
\hline & тем & руб & тем & py6 & тем & py6 & тем & py6 & тем & py6 \\
\hline Фактологический & 47 & 48 & 55 & 75 & 9,5 & 15 & 0,1 & $-0,05$ & $-0,07$ & $-0,1$ \\
\hline Операционный & 38 & 56 & 55 & 80 & 10 & 18 & $-0,6$ & $-0,8$ & 2,0 & 0,2 \\
\hline Эвристический & 30 & 39 & 50 & 75 & 9,5 & 17 & $-0,4$ & $-0,2$ & 0,2 & $-0,5$ \\
\hline Базовый & 47 & 50 & 50 & 85 & 10 & 17 & $-0,3$ & $-0,6$ & -0.15 & $-0,5$ \\
\hline Программный & 35 & 45 & 50 & 60 & 9 & 16 & 0,5 & $-0,1$ & 0,4 & $-1,1$ \\
\hline Сверхпрограммный & 39 & 48 & 35 & 60 & 7 & 13 & 0,35 & $-0,15$ & $-0,3$ & $-0,8$ \\
\hline
\end{tabular}

достичь практически все учащиеся. Исходным моментом для преподавателя является установка, что все его ученики способны полностью усвоить необходимый учебный материал и его задачей является - правильная организация учебного процесса, позволяющая подвести всех обучаемых к единому чётко заданному уровню ов- ладения знаниями и умениями.

По результатам итогового тестирования определяется, достигли ли обучаемые планируемого результата обучения. После этого выставляется итоговый балл и продолжается корректирующее обучение с теми, кто не 
достиг планируемых результатов.

\section{ЭКСПЕРИМЕНТАЛЬНАЯ АПРОБАШИЯ ТЕХНОЛОГИИ}

\section{Построение карт обученности}

Экспериментальная апробация технологии осуществлялась на агроинженерном факультете(1 курс) ИжГСХА и в школах выходного дня, работающих в системе «школа-вуз». Ежегодно тестировалось около 80-90 студентов и 200 слушателей школ выходного дня. Для каждого тестируемого по результатам тестирования строились карты обученности [11] (см. табл. 1).

Построение карт обученности осуществлялось с использованием разработанной нами компьютерной программы «Проект 1». Для исследования диагностики структуры обученности использовались тематические и рубежные тесты, разработанные на кафедре физики ИжГСХА.

Из анализа таблицы 2 видно, что структура тематических тестов почти одинаковая - до 15,0\% всех заданий проверяют базовые и программные знания. Для контроля умений на фактологическом и операционном уровне в тематических тестах служат 35,5 \% тестовых заданий. Заданий, проверяющих умения на эвристическом уровне, в тематических тестах - 29,0\%.

Результативность обучения проявляется в смене знака асимметрии распределений обученности в таксонах Ф и П и увеличении отрицательной асимметрии по модулю в таксонах О и Б, что свидетельствует о движении динамики обученности в сторону модели полного усвоения. Отрицательный эксцесс указывает на большую однородность обученности вблизи среднего значения [10].

Надежность предложенной модели проверена при проведении входного тестирования по курсу электротехники. Анализ результатов входного тестирования показал, что они коррелируют с результатами подготовки студентов по физике [5].

Предложенная технология диагностики будет полезна при оценке уровней сформированности компетенций обучаемых на разных ступенях образования.

\section{ЛИТЕРАТУРА}

1. Аванесов В.С. Определение, предмет и основные функции педагогической диагностики / В.С. Аванесов // Педагогическая диагностика. 2002. № 1. С. $41-44$.

2. Гмурман В.Е. Теория вероятностей и математическая статистика. Учебное пособие для вузов. 1999.

3. Давыдова Л.Н. Педагогическое диагностирование как компонент управления качеством образования: диссертация ... доктора педагогических наук / Л.Н. Давыдова. Астрахань, 2005. 343 с.

4. Звонников А.И., Челышкова М. Б. (2012) Контроль качества результатов обучения при аттестации (компетентностный подход): учеб. пособие. М.: Логос.

5. Белова Г.М., Родыгина Т.А. Тезаурусный подход к диагностике уровней обученности в системе непрерывного профессионального образования / Среднее профессиональное образование. 2007. №10. С.62-65.

6. Идиатуллин В.С., Русских И.Т. Тестовый мониторинг в высшей школе/ В сборнике: Мониторинг в образовании сборник научно- методических материалов. Институт усовершенствования учителей. Ижевск, 2000. С.115-118.

7. Михайлычев Е.М. Педагогическая диагностика в решении образовательных задач России первой половины XX века / Е.М. Михайлычев, Г.Ф. Карпова, Е.Е. Леонова // Педагогическая диагностика. 2005. № 3.C 3-9.

8. Михайлычев Е.М., Карпова Г.Ф., Леонова Е.Е. Поиск новых диагностических средств контроля результатов образования (в экспериментальной педагогике и психологии на рубеже XIX-XX веков) // Педагогическая диагностика. № 1. 2005. С.23.

9. Психологическая диагностика: учеб. пособие / под ред М. К. Акимовой. С. 35.

10. Русских И.Т. Разработка тестовой технологии диагностики структуры и динамики обученности в системе «Школа-вуз» диссертация на соискание учёной степени кандидата наук /Ижевск, 2003.

11. Русских И.Т. Структура обученности слушателей школы выходного дня / В сборнике: Аграрная наука на рубеже тысячелетий труды научно - практической конференции. Ижевская государственная сельскохозяйственная академия. 2001. С. 317 - 320.

12. Рыков В.В., Иткин В.Ю. Математическая статистика и планирование эксперимента. 2008.

@ Русских Ирина Таировна (Rit19861990@mail.ru), Родыгина Тамара Александровна (9058748130@mail.ru), Белова Галина Михайловна (fnpo@izhgsha.ru).

Журнал «Современная наука: актуальные проблемы теории и практики» 